\title{
NOTAS
}

\section{DE NUEVO SOBRE \\ ARTÍCULO + POSESIVO + SUSTANTIVO. TEXTOS VIZCAÍNOS DE LOS SIGLOS XV-XVIII ${ }^{1}$}

La construcción artículo + posesivo + sustantivo ha sido común en la Romania, pero mientras que en algunas lenguas se ha mantenido -en italiano, portugués, rumano, gallego o catalán-, en otras, como francés y español, prácticamente ha desaparecido. En lo que respecta al español, dicha combinación está suscitando mucho interés en la comunidad científica. Desde el trabajo ya clásico de Lapesa ${ }^{2}$, en el que se revelaban su cronología y particularidades en las obras literarias, en los últimos años se han hecho diversos análisis, mayoritariamente sobre textos literarios ${ }^{3}$, literarios y notariales ${ }^{4}$, en menor medida, sobre textos exclusivamente notariales ${ }^{5}$.

1 Una versión anterior de este trabajo se presentó en el "XXV Congrès Internacional de Linguistique et de Philologie Romanes”, Leopold-FranzensUniversität, Innsbruck, 2007.

2 RAFAel LAPESA, "Sobre el artículo ante posesivo en castellano antiguo", Estudios de morfosintaxis histórica del español, Gredos, Madrid, 2000, pp. 413-435.

${ }^{3}$ Véanse Ana Rodríguez Barreiro, "La sintaxis del posesivo en castellano medieval: una construcción característica”, Res Diachronicae, 2003, núm. 2, 284-293; Concepción CoMpany, "Determinantes al servicio del héroe. Artículo + posesivo en el Cantar de mio Cid", LCo, 33 (2005), 29-50; Enrigue Pato, "Dos construcciones posesivas en la obra de Santillana", en Estudios de historia de la lengua e historiografía lingüistica, coords. M.C. Cazorla, N. Contreras et al., Universidad, Jaén, 2005, pp. 365-378; JosefinA Albert, "La intencionalidad pragmática en el uso del posesivo en Berceo", en Actas VI del Congreso Internacional de Historia de la Lengua Española, ed. J.J. Bustos Tovar, Arco/Libros, Madrid, 2006, t. 3, pp. 2627-2637.

${ }^{4}$ Gloria Clavería, "La construcción artículo + posesivo en los siglos XIV y xv", en Actas del II Congreso Internacional de Historia de la Lengua Española, ed. M. Ariza, Pabellón de España, Madrid, 1992, t. 1, pp. 347-357; Rolf Eberenz, El español en el otoño de la Edad Media. Sobre el artículo y los pronombres, Gredos, Madrid, 2000; C. Company, "Frecuencia de uso y contacto lingüístico. La construcción artículo indefinido + posesivo en el español americano", $S p C, 2$ (2005), 131-156, y "Persistencia referencial, accesibilidad y tópico: la semántica de la construcción artículo + posesivo + sustantivo en el español medieval", RFE, 86 (2006), 65-103.

5 Carmen Hernández González, "Contribución al estudio del artículo 
Vistas las variaciones de frecuencia de uso de la combinación artículo + posesivo -no sólo entre autores de un mismo período, sino en un mismo autor e, incluso, en una misma obra ${ }^{6}-$, muchos de estos trabajos han subrayado su naturaleza estilística y su singularidad, en el sentido de que se trata de una construcción gramaticalmente huidiza. Atendiendo al primer aspecto, las investigaciones coinciden, asimismo, en la caracterización de la estructura como una expresión muy marcada, que aporta valor afectivo, énfasis y realce expresivo o retórico (entre otros, Lapesa, Clavería, Eberenz y Albert). Así las cosas, los estudios de Company ${ }^{7}$ han resultado fundamentales para la mejor comprensión de esta estructura, dado que ha descrito y demostrado su funcionamiento formal y semántico.

En síntesis, y de acuerdo con la hipótesis de esta autora, la combinación artículo + posesivo designa tres aspectos informativos estrechamente conectados: la accesibilidad del poseedor por medio del poseído, el vínculo de complementariedad entre ambos y su persistencia referencial ${ }^{8}$. En efecto, son construcciones de significado muy especializado para la accesibilidad del poseedor, ya que el poseído introducido por artículo + posesivo constituye una característica inherente y definidora del poseedor, lo que, simultáneamente, genera entre poseedor y poseído una relación de complementariedad referencial o integridad semántica, esto es, el poseedor lo es por tener el rasgo o cualidad señalado. Como ejemplo ilustrativo, véase el siguiente pasaje extraído de Company, en el que se señalan las propiedades definitorias de la autoridad real:

(a) Ca el poder del rey todo es en tres cosas. Lo primero en la su palabra. Lo segundo en la su pénnola con que escriue las sus cartas

ante posesivo", Hij, 1987, núm. 9, 121-147; M. Cristina Egido, "Artículo + posesivo + sustantivo en documentación leonesa del siglo xiı", en Trilcedumbre. (Homenaje al profesor Francisco Martínez García), coord. J.E. Martínez Fernández, Universidad, León, 1999, pp. 157-169.

${ }^{6}$ R. LAPESA, art. cit., p. 413.

7 Junto a los mencionados ("Determinantes al servicio...", "Frecuencia de uso y contacto..." y "Persistencia referencial..."), conviene citar C. ComPANY, "Gramaticalización y frecuencia de uso. Los paradójicos sintagmas con artículo + posesivo en el español medieval”, RHLE, 1 (2006), 5-30, y "Gramaticalización de secuencias sintagmáticas en construcciones. Fórmulas nominales con artículo + posesivo en el español medieval”, en Nuevas perspectivas en torno a la diacronía lingüística, coords. E. T. Montoro, M.A. López y F.J. Sánchez, Universidad, Granada, 2008, pp. 13-29.

8 Estos conceptos están tomados de Mira Ariel, "Referring and accessibility", JL, 24 (1988), 65-87 y TALMY GIVON, "The grammar of referential coherence as mental processing instructions", Ling, 30 (1992), 5-55. Cf. la definición ofrecida en estos trabajos con la propuesta por C. COMPANY, "Persistencia referencial...", esp. pp. 72-73. 
de lo que ha de mandar. La terçera en la su espada con que apremia a los sus enemigos e con que faze justiçia en los suyos ${ }^{9}$.

Este especial significado convierte las construcciones en formas idóneas para la explotación pragmática, de lo que se deriva, por una parte, su alta dependencia del contexto y, por otra, su comportamiento gramatical peculiar (ibid., p. 72). Dicho de otro modo, la construcción artículo + posesivo se transforma en una estrategia gramatical que informa que su núcleo, el poseído, es un rasgo inherente del poseedor y que, por ello, dicha construcción focaliza al poseedor.

En este marco, nuestro objetivo es rastrear la presencia y caracterizar el uso de artículo + posesivo en documentación notarial de Vizcaya, una de las zonas con presencia secular de la lengua vasca en contacto con el castellano ${ }^{10}$. Para ello se realizará una comparación cuantitativa y cualitativa con los resultados de los análisis sobre textos literarios y notariales y se aplicará la hipótesis desarrollada por Company sobre la semántica-pragmática de dicha estructura.

Con este trabajo contribuimos, por otro lado, a la caracterización lingüística de una parte del área vasca, tradicionalmente presentada en blanco en los mapas de la latinización peninsular y ausente en recopilaciones teóricas como el Lexikon der Romanistichen Linguistik (1990-2001), si bien en los últimos años el conocimiento de la lengua de estos documentos se ha incrementado notablemente gracias a los trabajos de Isasi y su grupo (SAI-Seminario Alfonso Irigoien) ${ }^{11}$. Según lo conocido hasta el momento ${ }^{12}$, la variedad romance de la documentación producida en Vizcaya entre los siglos XIV y XVI es castellano, con determinados rasgos específicos pero no exclusivos, con lo que esta zona quedaría inserta en lo que se considera el continuum dialectal norteño peninsular ${ }^{13}$.

9 "Persistencia referencial...", pp. 92-93; conservamos las cursivas del original.

${ }^{10}$ Geográficamente, la comunidad vascohablante se localiza a ambos lados de la frontera franco-española, a orillas del océano Atlántico, aunque desde el punto de vista administrativo, la mayor parte de su extensión se encuentra dentro del estado español; se conoce con el nombre de Comunidad Autónoma Vasca o País Vasco, y comprende los territorios históricos de Vizcaya, Guipúzcoa y Álava.

${ }^{11}$ Véase su página: littera.deusto.es/prof/isasi/prof/isasi/SAI/curriculum (consultada en agosto de 2008).

${ }^{12}$ Una síntesis de estas cuestiones en Sara Gómez Seibane y J. Luis Ramírez Luengo, "La historia del castellano en el País Vasco: recuento bibliográfico, trabajos desarrollados, perspectivas de futuro", RILI, 2007, núm. 10, 221-240.

13 Carmen Isasi Martínez, "El romance de la documentación vizcaína en el espacio variacional castellano”, en Lingüistica Vasco-Románica/Euskal- 


\section{DESGRIPCIÓN DEL CORPUS}

El corpus utilizado para este trabajo está constituido por documentación original de las villas vizcaínas de Bilbao, Portugalete y Lekeitio que, desde el punto de vista cuantitativo, entendemos que es suficiente (572 000 palabras aproximadamente) y cuya cronología se extiende desde la segunda mitad del siglo xv hasta finales del siglo XVIII (1798). Desde el punto de vista tipológico, los textos tardomedievales $(1519)^{14}$ son, fundamentalmente, documentos municipales reguladores de la vida en la villa y de sus instituciones ${ }^{15}$, conjunto que se ha enriquecido con documentación parroquial (el Libro de fábrica de la iglesia de Santa María de Lekeitio), que en sus diferentes asientos anota los aspectos más mundanos relacionados con la vida eclesial.

Por su parte, la documentación de la segunda mitad del siglo XVI al XVIII, pertenece exclusivamente a Bilbao ${ }^{16} \mathrm{y}$, a diferencia de los documentos tardomedievales, está constituida por textos tanto de temática relacionada con las actividades municipales (sentencias sobre límites, autos, diligencias y ordenanzas), como vinculada a la esfera de lo personal (testamentos, inventarios o declaraciones de testigos).

Erromantze Lingüística, eds. C. Isasi Martínez y S. Gómez Seibane, EuskoIkaskuntza, San Sebastián, 2006, pp. 209-227.

${ }^{14}$ A continuación, se citan estas fuentes primarias. En el caso de que no se hayan utilizado todos los documentos, se enumeran entre paréntesis los utilizados: Javier Enríquez, Concepción Hidalgo, Araceli Lorente y Adela Martínez, Libro de decretos y actas de Portugalete (1480-1516), Eusko Ikaskuntza, Donostia, 1988 [en adelante, 1988]; Colección Documental del Archivo Municipal de Lequeitio (1325-1474), Eusko Ikaskuntza, Donostia, 1992 (70, 73, 80, 83, 85, 87, 89, 91, 95, 98-100) [en adelante, 1992a]; Colección Documental del Archivo Municipal de Lequeitio (1475-1495), Eusko Ikaskuntza, Donostia, 1992 (110, 130, 134-135, 154-155, 158) [en adelante, 1992b]; Libro de visitas del Corregidor (1508-1521) y Libro de fábrica de Santa María (1498-1517) de la villa de Lequeitio, Eusko Ikaskuntza, Donostia, 1993 (2) [en adelante, 1993]; Libro de autos judiciales de la alcaldía (1419-1499) y Libro de acuerdos y decretos municipales (1463) de la villa de Bilbao, Eusko Ikaskuntza, Donostia, 1995 (2) [en adelante, 1995a]; Libro de acuerdos y decretos municipales de la villa de Bilbao (1509 y 1515), Eusko Ikaskuntza, Donostia, 1995 [en adelante, 1995b].

15 Fernando Pino Rebolledo, Tipología de los documentos municipales. Siglos XII-XVII, Universidad, Valladolid, 1991, pp. 37-38.

16 Para ello, se han utilizado los documentos publicados por SARA Gómez Seibane, Carmen Isasi Martínez y EnriQueta Sesmero Cutanda, Bilbao en sus documentos (1544-1694), Universidad de Deusto, Bilbao, 2007; Sara Gómez Seibane y J. Luis Ramírez Luengo, El castellano de Bilbao en el siglo XVIII: materiales para su estudio, Universidad de Deusto, Bilbao, 2007 [en adelante, 2007]. 


\section{Artículo Definido + POSESivo. Datos CuAntitativos Y CUALITATIVOS}

Los datos cuantitativos sobre el uso de artículo + posesivo en contraste con la construcción con posesivo sólo pueden observarse en la Tabla 1. Cabe precisar que de los recuentos se han eliminado las construcciones todo + artículo + posesivo, artículo + otro + posesivo y artículo + dicho + posesivo, puesto que en ellas la selección del artículo no depende exclusivamente del posesivo, sino también de los elementos todo, otro o dicho.

\section{TABLA 1}

Alternancia artículo + posesivo y posesivo.

Siglos XV-XVIII

\begin{tabular}{|l|c|c|}
\hline & artículo + posesivo & posesivo \\
\hline $1450-1500$ & $167(16.34 \%)$ & $1.022(83.66 \%)$ \\
\hline $1501-1519$ & $61(3.81 \%)$ & $1.600(96.19 \%)$ \\
\hline $1544-1600$ & $2(2.19 \%)$ & $91(97.81 \%)$ \\
\hline $1601-1700$ & $2(1.52 \%)$ & $131(98.48 \%)$ \\
\hline $1701-1800$ & 0 & - \\
\hline
\end{tabular}

A partir de los datos presentados, queda manifiesta la progresiva disminución de la frecuencia de aparición de artículo + posesivo a lo largo del siglo XVI y xvII, y su desaparición total para el xviıI. Este resultado coincide, a grandes rasgos, con la cronología propuesta por Lapesa a partir de textos literarios ${ }^{17}$, pero más aún con la señalada por Company ${ }^{18}$, para quien la fecha de extinción de la estructura artículo + posesivo es el siglo XVII.

No obstante, la aparición de artículo + posesivo en la segunda mitad del siglo xv en la documentación vizcaína es más elevada que

17 Según dicha cronología, el siglo xv es momento de declive y el siglo XVI, de desaparición (R. LAPESA, art. cit., p. 430). Igualmente, HAYWARD Keniston, The syntax of Castilian Prose. The Sixteenth Century, University of Chicago, Chicago, 1937, advirtió su esporádica presencia en la prosa literaria de la primera mitad del siglo xvi. Para el análisis de la frecuencia de uso de estas estructuras entre los siglos XIV y XVIII en comparación con otras construcciones posesivas, véase SARa Gómez SEIbane, "Evolución histórica y caracterización lingüística. Construcciones posesivas marcadas en documentación vizcaína (siglos XIV-XVIII)", en Segundas Jornadas de Lingüistica Vasco-Románica: nuevos estudios. Oihenart, eds. S. Gómez Seibane y J.L. Ramírez Luengo, Eusko Ikaskuntza, Donostia, 2008, pp. 185-198.

18 "Gramaticalización y frecuencia de uso...", p. 12. 
la señalada por Eberenz para la misma fecha ${ }^{19}$. Por tanto, el recurso a la secuencia artículo + posesivo en textos notariales parece, en principio, más elevado cuantitativamente y más dilatado temporalmente, característica advertida por Lapesa ${ }^{20}$.

Por otro lado, y centrándonos en el corpus vizcaíno que llega hasta 1519, el desglose de los datos en función del factor geográfico no ofrece divergencias que, en principio, puedan estar relacionadas con la distribución espacial de las ocurrencias. Como se advierte en la Tabla 2, no existen diferencias notables en la disminución de la frecuencia de aparición de artículo + posesivo entre la zona centro vizcaína (Bilbao y Portugalete) y la zona costera (Lekeitio), más allá de que la documentación de Bilbao presenta, en comparación con las anteriores, una menor frecuencia de uso de dicha estructura en el siglo xv y, simultáneamente, una disminución mucho menor en el XVI. Es decir, la combinación de artículo + posesivo en el corpus bilbaíno se mantiene baja pero constante ${ }^{21}$.

TABLA 2

Alternancia geográfica de artículo + posesivo + sustantivo y posesivo + sustantivo hasta 1519

\begin{tabular}{|l|r|r|}
\hline & artículo + posesivo & \multicolumn{1}{|c|}{ posesivo } \\
\hline Bilbao XV & $6(3.55 \%)$ & $169(96.45 \%)$ \\
\hline Portugalete XV & $30(34.88 \%)$ & $86(65.12 \%)$ \\
\hline Lekeitio XV & $131(17.07 \%)$ & $767(82.93 \%)$ \\
\hline Bilbao XVI & $19(2.24 \%)$ & $848(97.76 \%)$ \\
\hline Portugalete XVI & $24(8.98 \%)$ & $267(91.02 \%)$ \\
\hline Lekeitio XVI & $18(3.71 \%)$ & $485(96.29 \%)$ \\
\hline
\end{tabular}

${ }^{19}$ Esta diferencia quizá pueda explicarse porque el corpus estudiado por R. Eberenz (op. cit.) reúne, como se sabe, una tipología variada, en contraste con nuestro corpus, exclusivamente notarial.

${ }^{20}$ En efecto, R. LAPESA, art. cit., pp. 430-431 y 435, documentó la fosilización de la estructura con artículo en el lenguaje cancilleresco. Con posterioridad, Clavería (art. cit.) observó, igualmente, la mayor permanencia de dicha construcción en los textos notariales, en contraste con los literarios; no obstante, en sus cálculos incluía algunas de las construcciones con todo, otro y dicho que hemos eliminado de nuestros recuentos.

21 Simultáneamente, estos datos revelan que, en el ámbito de la documentación notarial entendida en sentido lato, la tipología textual no parece ser un factor explicativo de las diferencias de frecuencia entre artículo + posesivo y posesivo solo. Efectivamente, los textos de Bilbao y Portugalete son acuerdos y decretos, la expresión normativa característica de los poderes municipales; mientras que la de Lekeitio es documentación parroquial. Sin embargo, es, precisamente, en el mismo tipo textual -la documentación municipal-donde se registran mayores diferencias cuantitativas en el uso de la estructura artículo + posesivo. 
Pasando a lo cualitativo, y como se ha avanzado en (1), los estudiosos de la combinación artículo + posesivo han tenido dificultades en la caracterización de ésta, debidas a la pluralidad de factores que deben manejarse. No obstante, varias voces han propuesto la existencia de una jerarquía, según la cual los más importantes son los pragmáticos y, sobre todo, los semánticos ${ }^{22}$, factores ambos que, como se ha descrito, Company ha considerado responsables del significado de la estructura.

\section{TABLA 3}

Distribución de artículo + posesivo en función del poseedor. Siglos XV-XVIII

\begin{tabular}{|c|c|}
\hline Autoridad real & $127(54.7 \%)$ \\
\hline Autoridad religiosa & $82(35.3 \%)$ \\
\hline Autoridad civil & $13(5.6 \%)$ \\
\hline Particulares & $10(4.3 \%)$ \\
\hline
\end{tabular}

En lo relativo a la semántica de la construcción, encontramos en los documentos vizcaínos de los siglos Xv al xvin que los poseídos pueden ser tanto concretos (libro, vasallo, jurado, cuenta, casa) como abstractos (ira, cuestión, justicia). Sin embargo, lo primordial para entender el significado de esta estructura parece que no es tanto el carácter léxico del poseído cuanto la reiteración de unos determinados poseedores. Así, como revelan los porcentajes de la Tabla 3, el empleo de artículo + posesivo se documenta en más de la mitad de sus apariciones cuando el poseedor es el rey (la su alteza), fundamentalmente por medio de sus posesiones (al mi consejo, los mis regnos e sennorios, la mi rúbrica), personas vinculadas a su figura (los mis vasallos, del mi tesorero) o características de su persona (la su justicia, la mi yra), como se ejemplifica en (1):

${ }^{22}$ Cf. Eberenz, op. cit. A partir de lo expuesto en Eberenz (pp. 275290), parece desprenderse la existencia de una escala de factores influyentes en la selección de la construcción artículo + posesivo. Así, en la parte más baja de ésta, y como factor de escasa influencia, se situaría la función sintáctica del sintagma nominal en cuestión; en una posición intermedia se ubicarían los aspectos pragmáticos, como la situación comunicativa o el tono de los interlocutores; y, finalmente, en la parte superior de esa escala, es decir, como agente de máxima influencia en la aparición de artículo + posesivo se encontraría la semántica, como puede observarse cuando se usa esta construcción con las nociones y conceptos esenciales en una obra (pp. 286-287) o cuando se emplea con función textual, como mecanismo de correferencia para ayudar en la configuración del universo de sentido del texto (p. 289). 
(1) Porque rasonable e conbenible cosa es a los reyes e prínçipes de faser graçias e merçedes a los sus súbditos e naturales (L1473-1474, 277 [1992a] $)^{23}$; en el traer de las armas segund las trayan era grand deseruiçio de Dios e de su altesa e de la su justiçia, porque dello non se podrría recreçer otro vien (B1509, 67 [1995b]).

En segundo lugar, se encuentran las referencias a la cabeza de la Iglesia Católica (la su divina magestad), sus bienes (del su sacro palaçio) y aspectos religiosos (la nuestra santa fe católica), así como la mención a Jesucristo en la data de los documentos (anno del nasçimiento del nuestro saluador Ihesu Christo):

(2) En el nonbre de Dios e de la Virgen Santa María de quien proçeden las devidas e verdaderas cuentas, por ende yo, Iohan Martínes de Legarça, afirmándome a la su divina magestad (L1515, 55 [1993]).

En tercer lugar, con una frecuencia de aparición mucho menor se registran aspectos vinculados con el poder civil, es decir, con el ayuntamiento de las villas, como las posesiones materiales (los nuestros montes, las sus casas), sobre todo, e impuestos (del nuestro nasaje ${ }^{24}$, la su cuenta) y personas (los nuestros alcaldes, los nuestros jurados):

(3) alcaldes hordinarios de la dicha villa en este presente anno... damos en renta a vos, Miquelao Ybannes... todos los derechos del nuestro nasaje (L1463, 182-183 [1992a]); otra escriptura donde se contiene la conoçençia que los de Hondarroa fisieron de los nuestros montes e los mojones e límites (L1515, 55 [1993]).

Finalmente, y con menor presencia, se documentan las construcciones de artículo + posesivo cuyo poseedor es un individuo particular, de las que nos ocuparemos más adelante.

Conviene recordar, en este punto, lo señalado por Company a propósito de la accesibilidad total del poseedor por medio del poseído: los nominales introducidos por artículo + posesivo constituyen propiedades esenciales de un poseedor topical, de manera que el oyente sabe, por un lado, de qué trata y a qué se refiere el poseído y, por otro, conoce el vínculo poseedor-poseído, con lo que estos sintag-

${ }^{23}$ Los datos entre paréntesis corresponden a localización de los ejemplos en las transcripciones usadas como fuente para este trabajo (véanse las notas 14, 15 y 16). La inicial mayúscula se refiere al lugar ( $\mathrm{B}=$ Bilbao, $\mathrm{L}=$ Lekeitio, $\mathrm{P}=$ Portugalete), seguido de la data del documento y la página. Finalmente, entre corchetes se señala la fecha de publicación de la transcripción.

${ }^{24}$ El 'nasaje' es un pago o impuesto relacionado con la carga de las embarcaciones, en Carmen Isasi, David Álvarez, Soledad Gancedo, Josu Gómez, Sara Gómez, José L. Ramírez y Asier Romero, "Léxico vizcaíno medieval (siglos XIV-XVI)”, Oihenart, 2005, núm. 20, 73-201. 
mas no contienen una información nueva ${ }^{25}$. Por lo tanto, los poseídos, que en los testimonios (1)-(3) se presentan introducidos por artículo + posesivo (la artillería, los súbditos y naturales, la divina magestad, el nasaje y los montes, mojones y límites), constituyen rasgos básicos del poseedor (el rey, Dios y la autoridad civil), rasgos que, además, son conocidos por el oyente. Con todo, mientras que en el texto analizado por Company (Cantar de mio Cid) el recurso a esta combinación configura el universo del protagonista, en los documentos vizcaínos estudiados sirve para destacar el poder y autoridad del poseedor no sólo cuando es el emisor, sino también cuando se hacen referencias a él ${ }^{26}$.

Sin embargo, cuando la construcción artículo + posesivo tiene como poseedores individuos particulares y anónimos -vecinos de la villa-, sus posesiones (la su nao, los sus çorrones, las sus casas), impuestos (la su meytad de costa) o problemas (los sus debates e questiones) se registran, en un primer momento, acompañados únicamente del artículo definido o del posesivo y, en la segunda aparición, se presentan con la combinación de ambos elementos, como puede comprobarse en (4):

(4) que todos los debates e questiones que el dicho Diego Guerra ha e tiene contra los herederos de Ochoa Sánches de Arriaga... e para que çerca los sus debates e questiones que son entre ellos los bean e libren e determinen (B1463, 202 [1995a]); Reclamo que dieron sobre la casa que faze Martín Saes de Larrinaga... por el enbargo que el conçejo tenía echado a Martín Saes de Larrinaga en las sus casas que nuebamente las faze e edefica (B1509, 103 [1995b]); Juan Ynnigues... por quanto non tenía lugar para sus çorrones en el peso de la dicha villa le diesen lugar para poner los sus çorrones segund tenían otros (B1515, 228 [1995b]).

A la luz de estos testimonios, queda claro que las posesiones del rey, de los representantes de Dios en la tierra y del poder civil aparecen resaltadas mediante artículo + posesivo desde su primera enunciación -ejemplos (1)-(3)-, porque son intrínsecos, conocidos por el oyente y, por lo tanto, no exigen una presentación previa. Las posesiones de particulares de (4), en cambio, requieren, en primer lugar, aparecer con el artículo, es decir, presentarse y actualizarse o, desde la perspectiva del oyente, convertirse en realidades conocidas y accesibles al receptor. Y una vez que esto es así, el vínculo poseedor-poseído puede subrayarse por medio de un sintagma con artículo + posesivo.

25 C. Company, "Determinantes al servicio del héroe...", p. 33.

${ }^{26}$ Por ejemplo, la mención del escribano suele ser la siguiente: "escriuano e notario público sobredicho del dicho sennor rey en la su corte"; o la relación del conde de Haro con el rey y su consejo se enuncia así: "camarero mayor del rey, nuestro sennor, e del su consejo". 
Desde el punto de vista formal, la evidencia de que el poseído es un elemento conocido y característico del poseedor se manifiesta en el hecho de que los sintagmas con artículo + posesivo son mayoritariamente $-62.5 \%$ (144/232) - sintagmas sin modificador. En efecto, en estas construcciones los sustantivos no se acompañan de ningún modificador que añada información sobre el sustantivo, lo que implica que el poseído "es un referente autocontenido, bien conocido en la narración, que no requiere otra modificación o descripción” ${ }^{27}$. El restante $37.5 \%$ (87/232) presenta sintagmas con expansión o acompañados de un modificador, que puede ser un adjetivo, un sintagma preposicional o una subordinada relativa. No obstante, la mayor parte de estos sintagmas (82/232) -referidos, además, a la autoridad real, religiosa y civil y con alto grado de rutinización- presentan una adjetivación que, desde el punto de vista semántico, puede resultar redundante, pues no aporta nueva información, sino que insiste en las características ya conocidas del poseído.

Así, como puede observarse en los ejemplos de (5), lo esperable de Jesucristo en la religión católica es que sea el Salvador y que los condados y consejos del rey sean nobles y leales. Este tipo de adjetivación connotativa o descriptiva es la que Company (id.) registra en el Cantar en los sintagmas con artículo + posesivo y con modificador:

(5) anno del nasçimiento del nuestro saluador Ihesu Christo (B1463, 206 [1995a]); del su mui alto e noble consejo (P1484, 4 [1988]); del mi noble e leal condado (B1509, 136 [1995b]).

Por añadidura, y como se ha advertido, muchas de estas construcciones muestran un alto nivel de lexicalización, aspecto también destacado por Company ${ }^{28}$. Especialmente a partir del siglo Xv, artículo + posesivo se convirtió en una estructura con encaje en ciertos pasajes textuales y con un núcleo bastante predecible a partir del contexto, si bien en el corpus vizcaíno hay diferencias en el grado de rutinización. Efectivamente, hay unidades que se insertan siempre en un sitio concreto del discurso y que, por tanto, pueden considerarse parte de una fórmula ${ }^{29}$-como el caso de del nuestro saluador Ihesu Christo, inserta generalmente al inicio del documento para su datación-, mientras

27 C. Company, "Determinantes al servicio del héroe...", p. 34.

28 "Gramaticalización de secuencias...", pp. 19-23.

29 Entendida de acuerdo con la definición de 'fórmula fija' o 'estructura formulaica' presentada en José L. RAmírez Luengo: "estructura de significado fijo sin variación en sus formantes funcionales (o con variación sinonímica) que se repite de forma sistemática en una parte específica de una tipología textual específica a lo largo de un lapso temporal más o menos amplio" ("Notas sobre el futuro de subjuntivo en la Vizcaya bajomedieval", en Actas del V Congreso de Lingüistica General, ed. M. Villayandre Llamazares, Arco/Libros, Madrid, 2004, t. 3, p. 2325). 
que otras responden más bien al concepto de fórmula estructural, esto es, construcciones "con un llenado léxico restringido y una función pragmática constante" ${ }^{30}$, remitidas a propiedades y tareas de la autoridad real, como en la su corte o del su consejo ${ }^{31}$.

Sin embargo, en contraste con los testimonios de (5), cuando los poseídos son individuos anónimos, el tipo de modificador de los sintagmas introducidos por artículo + posesivo sí aporta contenido informativo a lo poseído. En efecto, se trata de sintagmas preposicionales y subordinadas relativas y adverbiales (6) que sirven para situar al poseído con mayor precisión con respecto al poseedor:

(6) edeficar de nuebo las sus casas de Caballa, que solian ser de los herederos de Ysasy (B1509, 78 [1995b]); las sus casas que nuebamente las faze e edefica en la Talaya (B1509, 103 [1995b]); para que çerca los sus debates e questiones que son entre ellos los bean e libren e determinen (B1463, 202 [1995a]); que mi cuerpo sea sepultado en la yglesia de señor San Pedro de Munguía y en la sepultura de la mi casa y solar de Cuaçaga, donde están enterrados mis aguelos y passados... Martín de Urquina y su muger casero de la mi casa de Cuaçaga (B1630, 87,89 [2007]).

En vista de lo anterior, el tipo de poseedor se revela como factor importante: cuando el poseedor es el rey, Dios o el poder civil puede focalizarse con la construcción artículo + posesivo sin necesidad de actualizar o presentar sus nominales poseídos; además, no suele acompañarse de modificador y, si lo lleva, no es informativa-

30 C. Company, "Gramaticalización de secuencias...”, p. 22.

31 La frecuencia de aparición de estas construcciones rutinizadas es ciertamente importante, puesto que suponen $50.4 \%$ (117/232) de los sintagmas con artículo + posesivo ("del nuestro saluador Ihesu Christo", 26.3\% [61/232]; "en la su corte", 20.7\% [48/232]; "del su consejo", 3.4\% [8/232]). Junto a estas construcciones se documentan otras fundamentalmente relacionadas con el poder real y el religioso. Precisamente, la rigidización léxica de la construcción junto con su marcado carácter pragmático impidieron que se generalizara en español, por lo que constituye una gramaticalización trunca o parcial (C. Company, "Gramaticalización y frecuencia de uso...", p. 7). El uso de documentación notarial es, sin duda, un factor determinante en la presencia de esta temática, así como lo es la cosmovisión de la época, con una marcada importancia de las figuras reales y religiosas. En esta línea de rutinización temática y léxica de la combinación artículo + posesivo deben interpretarse los casos detectados en la segunda mitad del siglo XVI ("la mi ánima”, B1565, 61 [2007]; “el nuestro primero padre Adán”, B1554, 46 [2007]), en el sentido de que estas estructuras están determinadas, probablemente, por el ars notariae de los escribanos. Véase, al respecto, CARMEN IsASI, "Escribanos vizcaínos en el tránsito a la modernidad", en Studia Philologica in Honorem Alfonso Irigoyen, eds. I. Túrrez, A. Arejita y C. Isasi, Universidad de Deusto, Bilbao, 1998, pp. 107-123. 
mente relevante. Sin embargo, si el poseedor es un individuo particular, el poseído se actualiza antes de aparecer en la construcción de artículo + posesivo, y sus modificadores son relevantes desde el punto de vista informativo.

\section{Artículo IndeFinido + POSESIVO. DATOs CUANTitativos Y CUALITATIVOS}

Considerando un y variantes de género y número como artículo indefinido $^{32}$, la frecuencia de aparición de este elemento en combinación con posesivo presenta porcentajes muy bajos para la segunda mitad del siglo XV y primer cuarto del XvI (Tabla 4). Estos datos confirman, por tanto, lo apuntado por Eberenz, quien señala que para el siglo XV las ocurrencias no superan el número de dos o tres, y por Clavería, que recoge cinco testimonios en los siglos XIV y XV. Para el primer cuarto del siglo XVI, si bien el porcentaje aumenta ligeramente en nuestro corpus, sigue resultando una presencia esporádica, al igual que en la prosa literaria ${ }^{33}$, y en fechas posteriores no se documenta ningún testimonio.

\section{TABLA 4}

Construcción artículo indefinido + posesivo y posesivo.

Siglos XV-XVIII

\begin{tabular}{|l|c|c|}
\hline & art. indefinido + posesivo & posesivo \\
\hline $1450-1500$ & $5(0.95 \%)$ & $525(99.05 \%)$ \\
\hline $1501-1519$ & $10(1.45 \%)$ & $687(98.55 \%)$ \\
\hline $1544-1600$ & 0 & - \\
\hline $1601-1700$ & 0 & - \\
\hline $1701-1800$ & 0 & - \\
\hline
\end{tabular}

Hasta el momento, los análisis diacrónicos realizados sobre la construcción con artículo indefinido + posesivo están relacionados con la gramaticalización de un(o)-una, es decir, con el proceso de debilitamiento del valor de cuantificación y progresiva adquisición de valores discursivos ${ }^{34}$. En este proceso, las variables que afectan al

32 Véase, al respecto, Manuel Leonetti, "El artículo", en Gramática descriptiva de la lengua española, dirs. I. Bosque y V. Demonte, Espasa, Madrid, 1999 , t. 1, pp. 787-890.

${ }_{33}$ H. Keniston, op. cit., p. 247.

34 Cf. C. Company, "Frecuencia de uso y contacto...". Aunque el debate sobre la adscripción categorial de un podría considerarse de importancia 
poseído, como rasgos léxicos, tipos de modificadores de los que se acompaña o grado de topicalidad y persistencia referencial son evaluados como índices del estado de gramaticalización de esta construcción como estructura introductora de entidades en el discurso.

En cuanto a la caracterización de las construcciones de la documentación vizcaína, hay que señalar, en primer lugar y en relación con el poseedor, la inversión del orden de los poseedores vistos en el caso del artículo definido. Se trata, así, de mayor a menor recurrencia, de poseedores particulares (9/15), personas vinculadas con el poder civil $(3 / 15)$, la autoridad real $(2 / 15)$ y la religiosa $(1 / 15)$.

Con respecto a la realidad poseída, en contraste con la preferencia medieval por entidades humanas ${ }^{35}$, encontramos que se seleccionan cinco poseídos [+humanos] (hijo, criado, sobrina) y diez poseídos [-humanos] (villa, negocio, carta), algunos de los cuales se presentan en (7):

(7) el dicho Juan Saes auía enbiado vn su padrón de cuentas (B1463, 218 [1995a]); tyene nesçesydad de yr en vn su negoçio de la villa a Castilla por vn mes (B1509, 112 [1995b]).

Esta noticia reviste cierta importancia-aunque debe tomarse con cautela $^{36}$-, ya que el aumento de la presencia de poseídos [-humanos]

secundaria por tratarse básicamente de una cuestión terminológica, hasta el siglo Xv se ha valorado que hay suficientes argumentos para considerar un y sus variantes una única entrada léxica como numeral y no como artículo (cf. C. Company, La frase sustantiva en el español medieval. Cuatro cambios sintácticos, UNAM, México, 1991). Con todo, ya en el siglo xiv hay ejemplos en los que, al formar parte del sujeto en enunciados genéricos, se aproxima mucho al uso moderno (MANUEL LeOnetTi, "Notas sobre sujetos genéricos indefinidos en español antiguo", en Actas del I Congreso Internacional de Historia de la Lengua Española, eds. M. Ariza, A. Salvador y A. Viudas, Arco/ Libros, Madrid, 1988, t. 1, pp. 495-499). Así pues, a partir del siglo xv, se ha observado un distanciamiento importante con respecto al funcionamiento típico del numeral (C. Company, "Frecuencia de uso y contacto..."; véase, también, Mar Garachana, "La extensión del artículo indefinido durante la baja Edad Media”, en Actas del VI Congreso Internacional de Historia de la Lengua Española, eds. J.J. Bustos Tovar y J.L. Girón Alconchel, Arco/Libros, Madrid, 2006, t. 1, pp. 687-697).

35 Veánse C. Company ("Frecuencia de uso y contacto...") y EnriQue Pato Maldonado, "La estructura posesiva «una mi amiga» en el español de Guatemala", en El indigenismo americano. T. 3: Actas de las Terceras Jornadas sobre Indigenismo Americano, eds. A. Palacios y A.I. García, Universitat, València, 2001, pp. 121-154.

36 Desde luego, no puede rechazarse la influencia del azar en este resultado, dada la escasez de exploraciones realizadas en este sentido. Son necesarios, pues, más trabajos sobre ésta y otras áreas peninsulares para confirmar esta primera impresión. 
permitió la adquisición de nuevos valores discursivos y su conversión en una estructura muy productiva en la variedad de contacto mayaespañol centroamericano ${ }^{37}$. Este cambio semántico se ha considerado propio del español americano ${ }^{38}$, pero, en vista de los poseídos del corpus vizcaíno, parece posible que en el castellano norteño peninsular esta tolerancia semántica se encontrara en marcha, en hipótesis, desde la segunda mitad del siglo $\mathrm{Xv}^{39}$.

Por otro lado, se ha conectado la presencia de modificadores con la cuantificación indefinida expresada por un(o)-una y, en consecuencia, con un estadio de gramaticalización en proceso en época medieval ${ }^{40}$. Atendiendo, en primer lugar, a la presencia de adjetivos, sintagmas preposicionales y relativas en nuestro corpus, se observa un equilibrio entre sintagmas con modificador (7/15) y sin él (8/15), sin que exista presencia/ausencia en función del tipo de poseedor. Por añadidura, la modificación aporta en todos los casos contenido informativo, ya sea en referencia a la autoridad real, a la civil o a los individuos particulares, como puede comprobarse en los ejemplos de (8). No obstante, se advierte una ligera disminución de la presencia de sintagmas con modificadores: de $60 \%$ en la segunda mitad del siglo Xv se pasa a $50 \%$ en el primer cuarto del siglo XVI:

(8) vn mi aluala escripto en papel e firrmado de mi nonbre (L1473-74, 278, [1992a]); Ferrand Sánches de las Rybas, fyel, tyene nesçesydad de yr en vn su negoçio de la villa a Castilla (B1509, 112 [1995b]); su muger en ella e vna su fyja moça que está prennada (B1509, 41 [1995b]).

En segundo lugar, en conexión con el grado de gramaticalización del artículo indefinido, cabe señalar que esta construcción introduce poseídos informativamente novedosos que se retoman posteriormente en el discurso (9/15) -véanse las ocurrencias de (9) -, si bien en otros casos (6/15) esta entidad no se presenta en

37 Como ejemplo ilustrativo de esta cuestión, reproducimos un pasaje de C. Company ("Gramaticalización y frecuencia de uso...”, p. 10), en el que se observa la gramaticalización de la estructura en una variedad del español americano y su paso a la oralidad y al habla popular: (b) "Y si no, pues muy sencillo, llene su vaso de jugo de naranja,...o un su vaso de chocolate con unas sus gotas de alcohol, o que tenga una su pastillita de butasolidina o aspirina" (Guatemala, hablante bilingüe de español-tzutujil).

38 C. Company, "Frecuencia de uso y contacto...".

$39 \mathrm{Al}$ menos la cronología permite plantear la hipótesis de que la ampliación del contexto originario pudo trasladarse del español peninsular al continente americano. Ahora bien, en ese caso habría que averiguar las causas, por un lado, de su desaparición del español peninsular y, por otro, de su arraigo en algunas zonas de América, aspecto este último tratado en C. Company ("Frecuencia de uso y contacto...").

40 C. Company, "Frecuencia de uso y contacto...”, p. 146. 
el contexto inmediato siguiente, es decir, en las treinta palabras siguientes:

(9) diole liçençia a vna su sobrina para que le acojan en la casa del ospytal las beatas por quanto, segund paresçe, quiere ser beata (B1509, 114 [1995b]); él tiene e posé çerca desta dicha villa vna su vina, en la qual dicha vina dixo que resçebía asas de dapno por cabsa que Juan Ochoa de Arana e otros sus vesinos comarcanos que tiene sus heredades pegado a la dicha vyna non querían (B1463, 233 [1995a]).

Con todo, conviene destacar el alto grado de mantenimiento léxico (9/15), especialmente del poseído, de los textos vizcaínos, en comparación con la documentación notarial estudiada hasta el momento $^{41}$, que, quizá por razones discursivas, apenas presenta persistencia del poseído y es muy escasa en el caso del poseedor. Este nivel de persistencia del poseído es mayor que el de los textos medievales (XIII-Xv) analizados por Company ("Frecuencia de uso y contacto...") y va en aumento en los propios documentos vizcaínos conforme avanza el tiempo. Así, en el primer caso advertimos que la persistencia referencial es casi el doble en los vizcaínos (60\%), frente a los medievales de la citada autora (37\%); y en el segundo, en nuestro corpus, la frecuencia de la persistencia referencial se incrementa $30 \%$ : de $40 \%$ en la segunda mitad del siglo xv, a $70 \%$ en el primer cuarto del XVI. De todo ello cabe concluir el aumento del uso de la estructura artículo indefinido + posesivo como introductora de entidades nuevas en el discurso; lo que, según la mencionada autora, es indicativo de un avance en la gramaticalización de un(o)-una como artículo.

\section{Conclusiones}

En este trabajo hemos comprobado la presencia de las construcciones artículo definido + posesivo y artículo indefinido + posesivo en la diacronía de la documentación vizcaína. La primera reduce gradualmente su frecuencia de aparición a lo largo de los siglos XVI y XVII, hasta su pérdida total para el XviıI, mientras que la segunda, de aparición más esporádica, no presenta testimonio alguno más allá del primer cuarto del siglo XVI.

Asimismo, hemos constatado la semántica de los sintagmas introducidos por artículo definido + posesivo en cuanto a las nociones de accesibilidad del poseedor por medio del poseído y al vínculo de integridad semántica establecido entre ambos con la finalidad de reforzar, así, el poder establecido.

41 Cf. C. Company, "Persistencia referencial...". 
No obstante, se han observado algunas diferencias, relacionadas con la actualización y modificación del poseído, que parecen depender del tipo de poseedor. En efecto, cuando los poseedores son la autoridad real, la religiosa o la civil, el recurso a la estructura artículo definido + posesivo responde a las características semánticas anteriormente descritas y, en la mayor parte de los testimonios, aparece sin modificación -y, si la presenta, es redundante. Por añadidura, en la referencia a este tipo de poseedores se ha advertido la presencia de artículo definido + posesivo en expresiones formularias con distinto grado de rutinización.

Cuando el poseedor es un individuo particular, en cambio, el poseído debe acompañarse primero de artículo definido (es decir, actualizarse) y, en próximas apariciones, cuando ya es una realidad conocida por el receptor, puede focalizarse con una construcción de artículo definido + posesivo. En lo concerniente a la atribución, estos poseedores seleccionan modificadores informativos y de contenido.

Por otro lado, la caracterización de artículo indefinido + posesivo se encuentra conectada con aspectos gramaticales y, en concreto, con la gramaticalización de un(o)-una como artículo. En esta línea, se ha apreciado que, en contraste con la tendencia medieval, en los textos vizcaínos se registra un mayor número de poseídos de rasgo [-humano], ampliación semántica de época tardomedieval que pudo llevarse, en hipótesis, al continente americano. Asimismo, en los usos de artículo indefinido + posesivo se han descubierto elementos que refuerzan la gramaticalización de un(o)-una como artículo. En concreto, una ligera disminución de la presencia de modificadores en el primer cuarto del siglo Xvi y la duplicación de la persistencia referencial en el contexto sintáctico inmediato desde la segunda mitad del siglo Xv.

Con todo, son necesarios nuevos trabajos sobre corpus de otras áreas que permitan comprobar las tendencias aquí señaladas con objeto de lograr un conocimiento más completo de esta construcción.

Sara Gómez Seibane Universidad de Castilla-La Mancha 